\title{
Is prostitution harmful?
}

\author{
Ole Martin Moen
}

Correspondence to

Dr Ole Martin Moen, Department of Philosophy, Classics, History of Art and Ideas, University of Oslo, Box 1020 Blindern, 0315 Oslo, Norway;

o.m.moen@ifikk.uio.no

Received 22 November 2011 Revised 13 February 2012 Accepted 20 July 2012 Published Online First 28 August 2012

\section{SLinked}

http://dx.doi.org/10.1136/ medethics-2012-100649

- http://dx.doi.org/10.1136/ medethics-2012-100833

- http://dx.doi.org/10.1136/ medethics-2012-101082

- http://dx.doi.org/10.1136/ medethics-2013-101389

- http://dx.doi.org/10.1136/ medethics-2013-101902

To cite: Moen OM. J Med Ethics 2014;40:73-81.

\section{ABSTRACT}

A common argument against prostitution states that selling sex is harmful because it involves selling something deeply personal and emotional. More and more of us, however, believe that sexual encounters need not be deeply personal and emotional in order to be acceptable-we believe in the acceptability of casual sex. In this paper I argue that if casual sex is acceptable, then we have few or no reasons to reject prostitution. I do so by first examining nine influential arguments to the contrary. These arguments purport to pin down the alleged additional harm brought about by prostitution (compared to just casual sex) by appealing to various aspects of its practice, such as its psychology, physiology, economics and social meaning. For each argument I explain why it is unconvincing. I then weight the costs against the benefits of prostitution, and argue that, in sum, prostitution is no more harmful than a long line of occupations that we commonly accept without hesitation.

\section{INTRODUCTION}

Most of us believe that prostitution is harmful. We believe that we are harmed if we sell sex and, perhaps, harmed if we buy sex. This harm, moreover, we consider to be of serious proportions. Selling sex is not regarded as on par with eating too much chocolate or getting a bad grade. Rather, it is regarded as so harmful that if it is ever permissible and appropriate to engage in prostitution, it must be as the last option available in a situation where the alternative is to suffer a life-threatening harm (such as starvation). Opinion polls support this line of thought. ${ }^{1}$

The belief that prostitution is harmful shapes how, privately and professionally, we approach the issue of prostitution. It also informs public policy debates. Even people with widely diverging views on prostitution legislation tend to share the underlying assumption that prostitution harms those who engage in it.

In this paper I challenge this underlying assumption, and I do so by arguing for the following conditional: if we accept the increasingly common view that casual sex is not harmful, we should accept that neither is prostitution. 'Casual sex', as I use the term, refers to sex engaged in for the sake of enjoyment or recreation without long-term commitments and emotional attachments. For all I argue here, casual sex might well be harmful, and if it is, so is prostitution. If casual sex is not harmful, however, I argue that prostitution-though, like most occupations, it has its downsides-is not harmful either. This conclusion, if correct, has farreaching implications for how we should approach the issue of prostitution in the healthcare sector and in public policy. ${ }^{\mathrm{i}}$

\section{What is 'prostitution' and what is 'harm'?}

'Prostitution', according to the Oxford English Dictionary, is 'the practice or occupation of engaging in sexual activity for payment'. ${ }^{2}$ For the purposes of this paper, this is an apt definition. 'Harm' is a more difficult concept, but I will here roughly speak of harm as that which is detrimental to well-being. Since I believe my argument is effective across a wide spectrum of theories of wellbeing, I shall not here commit to any specific theory. I exclude from the group of things and actions that are harmful, however, those things and actions that are detrimental to our well-being only because, and only to the extent that, we believe they are detrimental and thus act as if they were. The fact that a billion people might be disgusted and torn by guilt if they eat pork, for example, does not establish that eating pork is harmful. What is detrimental to people's well-being in this case, I maintain, is not the pork, but their religious convictions. I presuppose, in other words, a certain objectivism about harm.

In the following I shall first briefly discuss two views of sexual ethics: the view that casual sex is permissible and the view that it is not. Thereafter (in the section 'Nine arguments that prostitution is harmful') I examine arguments for the view that prostitution is harmful. These arguments incorporate diverse aspects of the practice of prostitutionits psychology, physiology, economics, social meaning and so on-and are meant to cover the ground of plausible arguments against prostitution. For each argument I explain why it is unconvincing. Thereafter I briefly weigh the costs against the benefits of prostitution, before I reply to two objections: first, that my argument runs contrary to basic, observable facts; second, that my argument rests on utopian presuppositions. ${ }^{\text {ii }}$

${ }^{\mathrm{i}}$ Though I take for granted here that casual sex is not harmful, I believe this paper can also be of value for those who dispute this premise. For those who believe that casual sex is mildly harmful, but that prostitution is very harmful, I hope my argument can make their estimation of prostitution more on a level with their estimation of casual sex. For those who outright reject all casual sex, my argument might perhaps be seen as a reductio ad absurdum of the pro-casual sex view. In what follows I deal solely with issues concerning well-being and harm. Thus my argument is likely to do more work for consequentialists than for deontologists.

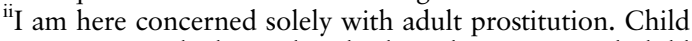
prostitution, which involves both underage sex and child labour, requires a separate discussion. 


\section{TWO VIEWS OF SEXUAL ETHICS}

In the paper 'Two Views of Sexual Ethics' David Benatar draws a distinction between two different views on the necessary conditions for permissible sex. In one view, which Benatar calls 'the significance view', sex is permissible only if it is 'an expression of (romantic) love' (author's parentheses). In the other view, which Benatar calls 'the casual view', sex need not have this significance in order to be permissible. ${ }^{3}$

This is an important distinction. I believe, however, that the labels Benatar has chosen-'the significance view' and the 'the casual view'-are misleading. They are misleading because they easily give the impression that while one view holds that sex can be romantically significant, the other view denies this. That, however, is not the case. 'The casual view' does not imply that sex is never romantically significant. It only implies that sex need not always be romantically significant in order to be permissible.

Clearly, proponents of what Benatar calls the significance view' might claim that 'the casual view' reduces sex to mere wriggling of meat, and thus makes all sex void of significance. That, however, is not a claim that proponents of 'the casual view' need to accept. They could explain why by drawing a parallel to eating. When a romantic couple dines at a lovely restaurant, their eating might well be romantically significant for both parties. What is, biologically, the mere satisfaction of a nutritional need is given deep personal meaning because of its social and psychological setting. It is not clear, however, the advocate of the "casual view' might argue, that one degrades eating as such and destroys one's capacity for appreciating romantic meals if one has earlier engaged in 'casual eating' or has been 'eating around', occasionally catching a cheap hotdog on the run. If this is right, then engaging casually in an activity that has the potential for romantic significance needs not destroy that activity's romantic significance on other occasions. If we accept this, then we would need a separate argument to explain why casual sex destroys sex even though casual eating does not destroy eating.

Rather than speaking of 'the significance view' and 'the casual view', therefore, I shall speak of 'the strong significance view' and 'the weak significance view'. While both views hold that sex can be romantically significant, only the strong significance view holds that all non-significance sex is impermissible. I will nowhere use the term 'casual view', though it could perhaps properly refer to the (implausible) view that sex is always merely casual and never romantically significant.

If the strong significance view is correct, it is very clear why prostitution is problematic. Though there might be cases where romantic love is present between a prostitute and a client (either one way or both ways), these are exceptions, and for the sake of the argument, I will take for granted that all sex between a prostitute and a client is sex without romantic significance. If casual sex is problematic, therefore, so is prostitution. If the strong significance view of sex is incorrect, however, it is no longer equally clear what the problem is with prostitution. At least, prostitution cannot be categorically ruled out for being sex without romantic significance, since sex without romantic significance is not per se a problem. As such, other features of prostitution would have to account for its alleged hazards. Let's examine nine influential arguments that purport to establish that such hazards exist.
This is a common argument with strong intuitive appeal. P1 seems undeniable. P2 is an empirical claim, and to assess it, it seems that we should consult psychological research on prostitution. When we do, we find that a significant number of prostitutes suffer from panic attacks, eating disorders, depression and insomnia, that many experience guilt, regret and remorse after having sold sex, and the suicide rate among prostitutes is six times that of the average population. ${ }^{\text {iii }}$ Since it is very implausible that such correlations are accidental, $\mathrm{P} 1$ and $\mathrm{P} 2$ both seem to be true. Thus we seem to have good reason to believe that prostitution is harmful (C) — even if we accept the weak significance view of sex.

The problem with this argument is that accepting that prostitutes often experience psychological problems, and that this correlation is not accidental, does not imply accepting that prostitution leads to psychological problems.

To make this point clear, we may turn to the literature on, and the debate over, homosexuality in the 1920s and 1930s. What we find in this literature is that homosexuals in the early 20th century also experienced guilt, regret and remorse, were significantly more prone to depression, eating disorders and insomnia than non-homosexuals, and had a significantly higher suicide rate than the rest of the population. ${ }^{78}$

These figures were used by opponents of homosexuality as allegedly scientific evidence that homosexuality is harmful. Today, however, most of us would claim that they misinterpreted the data. Though we would concede that many homosexuals did suffer from these problems, we would argue that the statistics themselves were insufficient to establish that there was anything inherently harmful in being a homosexual or in engaging in homosexual practice, and that the correlation was most likely due to the social treatment of homosexuals at the time. After all, homosexuals were subject to significant social stigma.

As long as we are merely spotting a correlation, therefore, we cannot exclude the possibility that to a larger or smaller extent, the same is true of prostitutes. Prostitutes, after all, are also subject to social stigma. 'Whore' and 'hooker' are highly derogatory terms, and Yolanda Estes, a former prostitute who is now a philosophy professor at Mississippi State University, claims in 'Prostitution: a subjective position' that if she had been open about her background all along, this would seriously have damaged her career. ${ }^{9}$ Indeed, as notes prostitution researcher Teela Sanders, we have a strong historical tradition for portraying sex workers as 'purveyors of disease, a social evil (and) a public nuisance .... ${ }^{10}$

I am not here making the strong claim that homosexuality in the early 20th century and prostitution today are perfect parallels. For all I argue (so far), it might well be that while there is nothing inherently harmful in homosexuality, there is something inherently harmful in prostitution. As such, there might be excellent reasons why prostitutes, even apart from the social stigma, naturally experience psychological problems. The stigma might even be proper. What I argue is merely that statistical correlation between prostitution and various psychological problems is not alone sufficient to conclude that prostitution leads to these problems. Since an argument from mere correlation with psychological problems alone fails to establish C, we will need additional arguments to show that prostitution is harmful.

\footnotetext{
iii There is an extensive literature on psychological problems related to prostitution. For an overview see Bullough et al, Day, and Farley and Barkan. $^{4-6}$
}

P2: Prostitution leads to psychological problems.

C: Prostitution is harmful.

\section{The correlation with psychological problems argument}

P1: That which leads to psychological problems is harmful. 


\section{The correlation with danger argument}

P1: That which is dangerous is harmful.

P2: Prostitution is dangerous.

C: Prostitution is harmful.

This is an argument formally similar to Argument 1 , and it seems equally forceful. P1 seems obvious, at least if the danger in question is excessive. $\mathrm{P} 2$, here as above, is an empirical claim, and consulting sociological and criminological research, we find that prostitution intimately correlates with venereal disease, criminal underground networks, drug abuse and violence. ${ }^{4}$ In a 1998 study, Melissa Farley and Howard Barkan found that 82\% of the prostitutes whom they interviewed had been physically assaulted. ${ }^{6}$ In 2008, Ulla Bjørndal and Bjørg Norli found that $72 \%$ had been victims of acts such as slapping, punching, kicking, robbing, burning, biting, raping and choking. ${ }^{11}$ Being subject to violence of this kind clearly seems dangerous (P2), and as such, it seems that prostitution is harmful (C).

Here again, however, we can use the history of homosexuality to show that the argument, as it stands, need not tell us much about the nature of prostitution. The reason why is that homosexual practice, when forbidden and condemned, also correlated strongly with venereal disease, underground networks, drug abuse and various forms of violence, and just as in the case above, these figures were used by opponents of homosexuality as allegedly scientific arguments supporting the view that homosexuality is harmful. ${ }^{12}$ Today, however, most of us would claim, again, that the data were misinterpreted. Though we would concede that many homosexuals did suffer from these problems, we would argue that the statistics were insufficient to establish that there was anything harmful inherent in being a homosexual or in engaging in homosexual practice. Rather, we would argue that the correlation most likely was due to the social and legal treatment of homosexuals at the time. After all, homosexuals were socially and legally oppressed.

Unless we wish to embrace a methodology that would have made us conclude, 70 years back in time, that homosexuality is harmful, we cannot conclude from these correlations alone that prostitution is harmful, for the social and legal treatment could be the source of these correlations as well. Indeed, it seems that this can be plausibly argued. In addition to the social stigma, the law (speaking here of current legislation in my own country, Norway) prevents prostitutes from joining labour unions, organising their work in brothels, renting a place where they can work, hiring security agencies, advertising and forming work contracts (regarding salary, working hours, working conditions, health insurance, retirement savings, and so on). It does not seem obviously wrong to hold that such legal restrictions contribute to pushing prostitutes away from civil society and make their lives rougher (this point is well argued by Almodovar ${ }^{13}$ ).

Again, there might be excellent reasons why a correlation with harmful activities would be likely to occur across a wide spectrum of legal treatments, or indeed, why a strict legal treatment is proper. To make the case for this, however, no argument from mere correlation will suffice. In order to convincingly argue that engaging in prostitution is harmful, one will need to point to something either intrinsic to the activity of buying and selling sex, or to a natural consequence thereof, that is harmful. The rest of this paper is concerned with arguments that seek to establish this.
This argument purports to say something about the very nature of prostitution, and as with Arguments 1 and 2 above, it seems intuitively plausible. It seems harmful to use people as objects (P1) and this seems to be what goes on when a client uses a prostitute to satisfy his sexual desires (P2). Thus it seems that prostitution is harmful (C).

Before we can assess this argument we must-to avoid equivocation-get a clear understanding of what we mean by 'objectification'. Let's examine two different senses of the term 'objectification' that are in use in the prostitution debate, one narrow and one wide.

In a narrow sense, such as Thomas Mappes' in 'Sexual morality and the concept of using another person', objectification means dealing with other persons by means of force or fraud, that is, to the practice of using others as objects that one may manipulate and dispose of as one pleases. In a broader sense, such as Howard Klepper's in 'Sexual exploitation and the value of persons', objectification is not restricted to force and fraud, but includes any treatment of another person as a means to one's ends without regard for that person's own ends. ${ }^{\text {iv }}$

On Mappes' narrow account of objectification, P1 seems true. On this account it is doubtful if $\mathrm{P} 2$ is true, that is, if prostitution involves objectification. However, though prostitution might in some or in many cases involve force or fraud, or both, it is not clear how this constitutes an argument against the very activity of buying and selling sex. It seems that using force or fraud is always (or nearly always) harmful, and the fact that it is harmful to force or defraud someone to $\phi$ is not a sufficient reason to conclude that it is harmful to $\phi$. The fact that it is harmful to force someone to marry, for example, does not show that marrying is harmful. Indeed, one could argue that in cases where force or fraud is used, we should not even speak of prostitution, but of rape or sexual slavery. If prostitution means buying and selling sex-and 'buying' and 'selling', to be applicable concepts, presuppose at least a thin notion of voluntariness-it seems just as unreasonable to label sex slavery 'prostitution' as to label someone who is filmed while raped a 'porn actress'. Thus Mappes' narrow account of objectification, though we should concede that it identifies a harmful form of objectification, does not render P2 true and thus does not establish that prostitution is harmful.

On Klepper's broader account, we face not just one problem, but two. The first problem is that on this account, P1 is doubtful, since many actions that we perform on a daily basis also qualify as objectification. I, for one, use my newspaper delivery man as an object in Klepper's sense of the term. Though I hope my newspaper delivery man is doing well, I cannot say that I do much to help him reach his goals. I use him as an object-a newspaper delivery object-and as a consequence, he is fungible to me. Since I am still in bed when he delivers my newspaper, I would not notice it if he were replaced by another, equally punctual, newspaper delivery man (or, indeed, by a newspaper delivery machine). Thus it seems that I use him as an object on Klepper's account. Unless we should grant that we harm our newspaper delivery men, shoemakers, baristas and lawyers by doing ordinary business with them, it seems that we cannot rationally regard all sorts of Klepperian objectification as harmful—at least not in any significant way.

\section{The objectification argument}

P1: That which involves objectification is harmful.

P2: Prostitution involves objectification.

$\mathrm{C}$ : Prostitution is harmful.
${ }^{\text {iv }}$ These two accounts are meant to be representative, not exhaustive. For a critical up-to-date overview of the debate over objectification in ethics and feminist theory, see the papers by Mappes, Klepper, and Papadaki. ${ }^{14-16}$ 
Even if we (generously) grant that P1 is true on Klepper's account objectification, it is not clear, however, how prostitution qualifies as such objectification-or, at least, how prostitution qualifies as objectification to a larger extent than activities that undeniably appear harmless. As Irving Singer has pointed out, 'there is nothing in the nature of sexuality as such that necessarily ... reduces persons to things', and the reason for this, Singer explains, is that there is something fundamentally reciprocal to sex. ${ }^{17}$ Bordering to this, Thomas Nagel points out in 'Sexual perversion' that a crucial aspect of sex is that we tend to derive pleasure from our sexual partner's pleasure. ${ }^{18}$ If Singer and Nagel are right, it seems that since a prostitute sells sex, it is not unlikely that at least to some extent, it matters to the client how she feels. Prejudice aside, it could be argued that prostitution is one of few trades where it is natural that the buyer to some extent cares for the seller. Perhaps for this very reason, it seems that prostitutes are less fungible than sellers of most other services. It seems that a buyer of sex would care more about what prostitute he has sex with than I care who delivers my newspaper, and it also seems that a client would be more likely to build a personal relationship with his long-term prostitute than I would with my long-term newspaper delivery man. Of course, there could be (and sadly, are) extremely objectifying clients who do not care the least about those whom they pay for sex. Even if we grant that such carelessness is harmful, however, this is not an argument against prostitution as such, since it fails to show that there is something inherent in the activity of buying and selling sexual services that leads to objectification or makes objectification likely.

Thus P2 is doubtful on Mappes' account, and P1 and P2 are doubtful on Klepper's account. Unless we can find an objectification argument that appeals to a harmful form of objectification and, at the same time, applies to prostitution, we need separate arguments to show that prostitution is harmful.

\section{The exploitation argument}

P1: That which involves exploitation is harmful.

P2: Prostitution involves exploitation.

$\mathrm{C}$ : Prostitution is harmful.

While objectification is the practice of using other persons as objects, exploitation is the practice of profiting unduly from others' work. If agent A works productively all day, yet earns almost nothing, while agent B earns what is rightfully A's, then B exploits A. This seems to harm A. If this is right, and prostitution involves such exploitation (P2), then prostitution is harmful (C).

For the sake of the argument, I will grant that P1 is true. It is unclear, however, if $\mathrm{P} 2$ is true-or, at least, if buying and selling sex involves or leads to more exploitation than buying and selling other goods and services. Even in today's context-a context with discriminating laws and social stigma-prostitutes do not seem to be significantly more exploited than others. For one, there are luxury prostitutes who earn significantly more than society's average income. Though these, of course, are exceptions, the income for ordinary prostitutes also appears to be fairly good, at least when compared to other kinds of lowskill, labour-intensive, and female-dominated work, which is the realistic alternative for most people engaged in prostitution. According to labour economists Lena Edlund and Evelyn Korn, prostitutes have an average yearly income between two and six times that of other women in this group. ${ }^{19}$ Similar findings have been replicated in other studies. Roger Matthews, in a survey conducted in London in 1996, found that prostitutes earned almost three times that of other manual workers. ${ }^{20}$ In a more recent survey conducted in Chicago, Steven Levitt and Sudhir Alladi Venkatesh found that street prostitutes on average make $\$ 25-\$ 30$ per hour. $^{\mathrm{v}}$ That is perhaps not a huge salary, but it is four times the minimum wage. ${ }^{\mathrm{vi}}$ Neither is it clear that pimps exploit prostitutes to the extent that we often assume. According to Edlund and Korn, the spot-like nature of prostitution renders it hard for pimps to profit, and in a 1995 survey, Lee Lillard found that less than 6\% of Los Angeles' prostitutes share income with a pimp. Shyamala Nagaraj and Siti Rohani Yahaya, studying non-Western prostitution, found that in Malaysia, prostitutes on average share $2 \%$ of their income with pimps (see figures in Edlund and Korn ${ }^{19}$ ).

Clearly, there is still profit involved in organising prostitution. That, however, fails to single out prostitution as a harmful profession, since profit is involved in organising virtually all professions. It seems, moreover, that a brothel-at least when run in a civilised manner-has the potential to contribute to the profit of a prostitute much the same way a hairdressing salon might contribute to the profit of a hairdresser, by providing facilities, steady income, safety, advertising, etc. This is supported by the findings of Levitt and Venkatesh, according to which prostitutes working under pimps on average earn more per week than prostitutes working alone-even though they work fewer hours and perform fewer tricks. ${ }^{21}$ For these reasons, we cannot take for granted without further argument that all profiting from prostitution has an exploitive nature.

Neither can we take for granted that when extremely poor women (or men) sell sex, and are harmfully exploited when doing so, it is the selling of sex-and not the poverty-that is the genuine source of the harm. Within the context of extreme poverty, exploitation can take place in most professions. This does not establish that these professions are harmful. The fact that construction work performed $15 \mathrm{~h}$ a day without safety equipment is harmful, does not establish that construction work is harmful. Similarly, the fact that selling sex $15 \mathrm{~h}$ a day without safety equipment is harmful, does not establish that selling sex is harmful. It only establishes that selling sex can be practiced in a harmful manner, which is uncontroversial.

\section{The male dominance argument}

P1: That which involves male dominance is harmful.

P2: Prostitution involves male dominance.

$\mathrm{C}$ : Prostitution is harmful.

This feminist critique of prostitution also seems forceful. Male dominance seems unjust and harmful (P1) and when women earn a living by satisfying men's sexual desires, what goes on looks like male dominance (P2). Thus it seems that prostitution is harmful $(\mathrm{C})$.

Though I believe we should grant P1, it is not clear that P2 is true.

A first problem with P2 is the fact that prostitution is manifold, and that there are male and female prostitutes serving male and female clients. Even if we focus exclusively on stereotypical prostitution involving female prostitutes and male clients, however, it is not clear that male dominance is involved. Though there are many ways to account for the feminist charge of male dominance, I will here consider an influential argument put forth by Carole Pateman in 'Defending prostitution: charges

${ }^{\mathrm{v}}$ The implications of these findings are discussed in Levitt and Venkatesh, and Levitt and Dubner. ${ }^{21} 22$

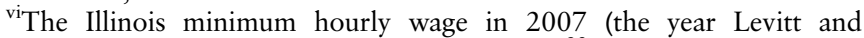
Venkatesh conducted their research) was $\$ 6.50 .^{23}$ 
against Ericsson' vii Pateman argues that 'prostitution remains morally undesirable, no matter what reforms are made, because it is one of the most graphic examples of men's domination over women'. She supports this by arguing that a market demand for sexual services is the result of a 'culturally distinctive form of masculinity (induced) into the unconscious development of little boys', and that Hegel and 'feminist interpretation of psychoanalytic theory' can help us grasp why. According to Pateman, ' $(t)$ he masculine sense of self is grounded in separateness (from femininity)', and 'Hegel showed theoretically in his famous dialectic of mastery and servitude that a self so conceived always attempts to gain recognition and maintain its subjective isolation through domination'. Men thus experience a need to 'affirm themselves as masters' and 'prostitution is the public recognition of men as sexual masters. ${ }^{26}$

This is not convincing. Even if we grant that the psychological mechanism which Pateman describes could perhaps lead to prostitution, her argument would only be effective against acts of prostitution motivated by a masculine desire to gain recognition and maintain identity by dominating the gender according to which men define themselves as the opposite. This appears to be a gross overtheorisation of men's willingness to pay for sex.

Even if we (generously) grant that this is in fact the mechanism behind all or most acts of prostitution, however, it is still not clear why it follows that prostitution is harmful. What Pateman has argued is that prostitution is 'one of the most graphic examples of men's domination over women', that is, that prostitution is a part of social life where it is clearly expressed that we live in a male dominated society. It is not clear, however, how this has any bearing on the harmfulness of prostitution, for even if $B$ is a product of $A$, and $A$ is harmful, it follows neither that B itself is harmful nor that B is indirectly harmful by reciprocally promoting A. For all Pateman has argued, prostitution could be a mere by product or a litmus test, which by itself is harmless. If Pateman seeks to argue not only that society at present harms women (which perhaps it does), but that prostitution is harmful, her argument fails. viii

A way to supplement Pateman's argument, suggested by Debra Satz, is that prostitution is harmful because it is degrading, and since most prostitutes are women, prostitution degrades women (this is a species of the argument that B is indirectly harmful by reciprocally promoting A). ${ }^{29}$ There are, however, two serious problems with this further argument. First, it relies on a troubling form of collectivism in judging the prostitute as a representative of one of the groups to which she belongs. ${ }^{\text {ix }}$ Second, if prostitution is degrading, it seems that it must be degrading in virtue of something. Thus calling prostitution 'degrading' takes for granted, rather than establishes, that there is something troubling about prostitution. As such, we are back

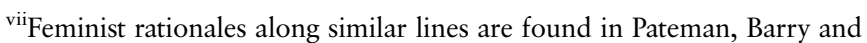
Farley. ${ }^{24-26}$ For a methodological critique of these approaches to prostitution research, see Weizer. ${ }^{27}$

viii This objection has also been raised by Scott A Anderson: '... radical feminists have failed to explain clearly why selling sexual recreation might itself be particularly problematic - that is, why open commerce in sex would make things worse for women than they are anyway in a patriarchal, capitalist society'. ${ }^{28}$

${ }^{1 x}$ Even if the assumed collectivism is legitimate, however, the claim is empirically questionable. Peter de Marneffe writes: 'Here we must wonder, though, whether women as a group are more victimized by sex discrimination in nations where prostitution is tolerated, such as The Netherlands and Germany, than they are in the USA, where it is not'. ${ }^{30}$ Another serious problem is that this objection does not fit well with male prostitution.
}

in the search for substantial reasons to believe that prostitution is harmful. ${ }^{\mathrm{x}}$

\section{The economic dominance argument}

P1: That which involves economic dominance is harmful.

P2: Prostitution involves economic dominance.

C: Prostitution is harmful

This is also an argument with strong intuitive appeal. Economic dominance, which we might define as the use of monetary power to subordinate a person to another person's will, seems harmful (P1). Since such subordination seems to be involved in prostitution (P2), it seems that prostitution is harmful (C).

I believe this argument can be put in at least three different ways, appealing to three different aspects of prostitution that supposedly give rise to economic dominance. Let's examine these separately.

First and most crudely it can be argued that there is something intrinsic to the roles of 'buyer' and 'seller' that tends to put the buyer, who has the money, in a dominant position over the seller, who must give up what she has in order to get the money she needs, and that this applies to prostitution. This is a weak argument, however, since it applies to a problematically large number of cases. Thus it is easy to come up with counterexamples. Consider, for example, a grocery store owner and a man buying bread or a drug dealer and a man buying drugs. In these cases, it is everything but clear that the buyer has the upper hand, even though the buyer supplies the money and the seller supplies the goods. As such, we cannot use the labels 'dominator' and 'dominated' categorically on either the buyer or the seller side, and as such, this cannot be used to establish that prostitution involves economic dominance.

An alternative reason why prostitution involves economic dominance could be that, at least in the majority of cases, there is a significant difference in economic power between the rich buyer and the poor seller, and it could be argued that this involves or makes likely that the rich party takes a dominant role in the transaction. This is also a weak argument, however, since we all take part in economically asymmetrical transactions on a daily basis, and we seem to do so without being harmed. Whenever I buy an airline ticket from KLM, an electronic device from Apple, or a hamburger from Burger King, I engage in a transaction where I have significantly less economic power than my trading partner. This does not harm me.

A third variant of the argument could appeal, not to the relative difference in economic power between the prostitute and the client, but to the absolute economic power of the prostitute, and to the fact that the prostitute might often be so desperately poor that in order to earn a living, she must satisfy all of her clients' whims. Such cases are clearly tragic, but acknowledging this seems rather to be an argument that extreme poverty is harmful than an argument that prostitution is harmful, sinceas in the exploitation argument-nothing in particular is said about the practice of buying and selling sex.

As such, it is unclear why it should follow from the nature of prostitution that the client holds a dominant position over the

${ }^{\mathrm{x}}$ The rationales offered by Pateman and Satz clearly do not exhaust the range of arguments against prostitution put forth in the feminist literature. I hope and believe, however, that the strongest additional arguments are adequately dealt with in other sections of this paper (see especially 'The objectification argument', 'The exploitation argument', 'The economic dominance argument' and 'The selling one's body argument'). For a philosophical overview of feminist views on prostitution (for and against) see Anderson. ${ }^{28}$ 
prostitute. Indeed, it seems that we might flip this common argument on its head and claim that the prostitute naturally holds a dominating position over the client. After all, what goes on in an act of prostitution is that two parties have sex, but one party, the client, is required to pay in order to be allowed to participate. If he will not pay, or he cannot pay, he is not allowed in. After the sex has come to an end, moreover, the client is left with nothing (but ebbing pleasure) while the prostitute is left with money.

Appeals to economic dominance, therefore, do not seem to establish that prostitution is harmful. To account for the alleged harm of prostitution, we need to say something more specific about the very actions involved in buying and selling sex specifically. I will now examine three arguments that do.

\section{The selling one's body argument}

P1: That which involves selling one's body is harmful.

P2: Prostitution involves selling one's body.

C: Prostitution is harmful.

This argument says something substantial and seemingly forceful about prostitution. It seems harmful to sell one's body (P1) and it also seems that prostitution involves just this (P2). As such, it seems that prostitution is harmful (C).

Before we can assess this argument, we must-to avoid equivocation-get a clear understanding of what we mean by 'selling one's body'.

It seems that the phrase 'selling one's body' can mean at least three different things. It can mean (1) selling one's body in the same way that one sells other commodities, such that after one has sold it, one no longer has any claim on it and the buyer may dispose of it as he pleases. Alternatively, 'selling one's body' can mean (2) renting out one's body for a certain period of time without restrictions on its use in the rental period, or it can mean (3) renting out one's body for a certain period with restrictions on its use in the rental period. ${ }^{\mathrm{xi}}$

Selling one's body according to (1) is clearly harmful. It is very doubtful, however, if this is an apt description of what goes on in prostitution. Point (1) describes slavery, not buying and selling sex, and it is uncontroversial that slavery is harmful. The same goes for selling one's body according to (2), since there are clear restrictions on what a client can rightfully do to a prostitute. A client cannot rightfully beat up a prostitute any more than he can beat up a hairdresser or a plumber. (It is true that in many societies, violence against prostitutes is taken less seriously than violence against non-prostitutes. That, however, should speak against those societies, not against prostitution.) To the extent that prostitution involves selling one's body, it seems that it must be according to (3), which is a much weaker account of 'selling one's body' than the catchphrase hints to.

On this account, however, it is no longer clear that selling one's body is harmful, since prostitution is far from the only profession where bodies are sold in this sense. Pateman argues that prostitution is indeed singled out as the body selling profession, but in arguing for this, she compares the services offered by prostitutes solely with the services offered by counsellors. ${ }^{26}$ That is not a very interesting comparison, however, since counsellors offer some of the least bodily services on the market. More interesting professionals to compare with are dancers,

\footnotetext{
${ }^{\mathrm{xi}}$ This taxonomy roughly coincides with Joel Feinberg's taxonomy of strong and weak waiving of rights, and relinquishing of rights. For an recent application of Feinberg's taxonomy to prostitution see Liberto. ${ }^{31}$ For Feinberg's original discussion, see his 1978 paper. $^{32}$
}

masseuses, sumo wrestlers and football players. Though few would argue that these professionals are significantly harmed, it seems undeniable that they sell their bodies according to (3). As such, it seems that making money from bodily work is at least not categorically harmful.

To single out prostitution, one might twist the argument by saying that in the same way selling does not really mean selling, body does not really mean body. One might argue that what matters is not that prostitutes rent out their bodies as such, but that they rent out a specific part of their bodies, namely their genitals. This can seemingly single out prostitutes, since dancers, masseuses, sumo wrestlers and professional football players do not earn money from renting out and doing jobs with their genitals.

In reply to such an argument, Martha Nussbaum has offered the example of a colonoscopy 'artist' who is paid and consents to having her colon used by medical researchers to develop efficient and comfortable colonoscopy equipment. This, Nussbaum admits, would be a strange occupation indeed, but it would not seem harmful in the sense and to the extent that most of us believe that prostitution is harmful (even though, as Nussbaum writes, the colonoscopy artist is 'penetrated by another person's activity - and, we might add, far more deeply penetrated than is generally the case in sex'). ${ }^{33}$ If Nussbaum is right, the fact that prostitution involves making money from using one's genitals is insufficient to establish that prostitution is harmful. ${ }^{\text {xii }}$

An alternative suggestion could be that the harm lies not in the seller having her genitals interfered with, but in the seller having to interfere with the buyer's genitals. This distinguishes the prostitute from the colonoscopy artist. The problem with this suggestion, however, is that although it would not imply that the colonoscopy artist is harmed by the colonoscopy, it would imply that the medical doctor performing the colonoscopy is harmed-at least if he is paid by the colonoscopy artist for doing his job. ${ }^{\text {xiii }}$ This suggestion seems even less plausible than the suggestion that the colonoscopy artist is harmed.

A last suggestion falling under the 'selling one's body' category could be that the harm lies neither in the genitals of the prostitute nor in the genitals of the client, but in the interaction of their genitals. This would seemingly single out prostitution from all other body-selling professions, since prostitutes are presumably the only ones who make money from genital interaction. It is unclear, however, how it could be harmful that genitals A and genitals B touch and interact for payment if individually touching and interacting with genitals $\mathrm{A}$ and genitals $\mathrm{B}$ for payment is quite harmless. At least, it seems that if one wants to argue that such interaction is harmful, focusing solely on the bodily movements involved will not do the trick. To account for the alleged harm, then rather than looking merely to the body and the bodily movements, one should look to the movements' sexual meaning and to the mental side of making money from providing sexual services, and seek to locate the harm here. This is the aim of the remaining two arguments.

\section{The habitual faking argument}

P1: That which involves habitual faking is harmful.

P2: Prostitution involves habitual faking.

C: Prostitution is harmful.

\footnotetext{
xiiStrictly speaking, the colon is not part of the genitals. It is hard to see, however, how this could be argumentatively relevant, since we can presumably change the example to involve gynecology rather than colonoscopy without deriving at different results.

xiii Perhaps the CEO of the medical company wants the equipment tested on her to ensure its quality.
} 
One psychological hardship associated with selling sex is that it requires one to fake one's sexual responses. Perhaps Nagel's mutual enjoyment theory (see 'The objectification argument'), assuming it is correct, leads not to the client caring for the prostitute's enjoyment, but to the prostitute being required to pretend that she enjoys having sex with her client. This seems quite plausible, and according to Estes, it is a brutal fact about prostitution that 'every visible response (of the prostitute) must address the client's desires and wishes'. This, Estes claims, can make the prostitute 'cognitively and emotionally confused' if it is done consistently and over time. Indeed, Estes argues, this can destroy a prostitute's sex life, and she asks, seemingly rhetorically, whether someone who has worked as a prostitute will ever be able to 'switch on' her feelings when with her lover'. 9 To the extent that the prostitute will not, it seems that P1 and P2 are true, and thus that prostitution is harmful (C).

There are, however, problems with this argument as well. A first problem is that it is not always clear that 'every visible response must address the client's desires and wishes'. Though some clients might demand this, others might not. As such, there seems to be limits to how much faking is required.

Regardless of the possibility of a lack of demand for excessive faking, however, we should concede that at least some faking is intrinsic to, or is made very likely by, prostitution. Thus it seems that a prostitute still could be led to making a habit out of faking, and thus that $\mathrm{P} 2$ remains.

Even if we grant that P2 is true, however, it is not clear that P1 is true. As in several of the above arguments, the allegedly harmful feature appealed to is also present in professions that we do not think of as harmful. A good example here is professional acting. An actress makes money from faking: from pretending that things are otherwise than they are. This can be rough: she can be required to play in a light-hearted comedy the day after a friend of hers has died or in a tragedy the day after she has gotten married. If she engages in this for decades, it seems that she could and would be making a habit out of faking. We do not, however, think of acting as harmful. On the contrary, we usually think of acting as enriching. A natural question to ask, then, is why the same cannot be true of prostitution. Prejudice aside, it does not seem impossible that a prostitute could handle her acting the same way actresses do and thus manage to keep her sex with a lover distinct from her sex with a client the same way an actress keeps the sorrow she expresses over Hamlet's death distinct from the sorrow she expresses at her friend's funeral. At least, an argument would have to be made as to why-granted the weak significance view of sex-a prostitute could not do this.

The habitual faking argument, therefore, seems not to be effective as long as it does not explain how faking while having sex is fundamentally different from faking in other areas of life. To make the case that it is, one must seemingly appeal to something in the very personal and emotional nature of sex.

\section{The selling one's soul argument}

P1: That which involves selling one's soul is harmful.

P2: Prostitution involves selling one's soul.

$\mathrm{C}$ : Prostitution is harmful.

If we translate 'soul' into less mystical terms, and use it to refer to our deepest values, emotions and character traits, then this argument has a plausible P1. The arch example of selling one's soul is perhaps to sell the position as one's closest friend. Close friendships are thought to flow from our deepest values, emotions and character traits, and this seems to be the reason why close friendships should not (or perhaps could not) be sold. The intimacy of sexual relations might make them share this characteristic with friendships (P2), and this might in turn explain why prostitution is harmful (C).

The problem with this argument is that it is forceful only on the strong significance view of sex. If the strong significance view is false, it is not clear why selling a close friendship is a good parallel to selling sex. On the weak significance view, in which casual sex is permitted, it would be fine to engage in sexual actions without being emotionally involved.

A counterargument to this reply could be that even if the weak significance view is correct, complete emotional detachment is not possible, at least not as long as the person involved has a healthy, non-repressed emotional life. There might, accordingly, be some personal elements included in all sex, even though these might not be sufficiently strong to warrant the strong significance view of sex. I believe this is a sound counterargument. Even if we concede that there are certain personal elements involved in all sex, commercial sex included, however, this needs not imply that prostitution is harmful-or, at least, not harmful to a significant degree. After all, people sell personal elements in a long line of professions that we do not consider harmful. Nussbaum provides the example of a philosophy professor, like herself, who 'takes money for thinking and writing about what she thinks - about morality, emotion, the nature of knowledge' even though these are 'all parts of a human being's search for understanding of the world and oneself'. ${ }^{38}$ A philosophy professor, Nussbaum notes, sells her soul in this sense, and should expect, as part of her work, that strangers invade her private space: on the one hand, she could be facing students who are not worthy of her philosophical attention, yet still receive it for payment. On the other hand, she could experience unexpected arguments that shake her grounds in settings where she must remain calm and professional. A philosophy professor, therefore, seems to sell her soul, and the same might plausibly be said about professional musicians, authors, psychologists, priests, medical doctors, nurses, teachers and kindergarten workers. Granted the weak significance view of sex, it is not clear why a prostitute sells her soul to a larger extent than these professionals do. As such, we are still not given a convincing reason why prostitution is harmful.

\section{COSTS AND BENEFITS}

Even though, for the reasons provided above, I do not believe that prostitution is harmful in the ways and to the extent that is traditionally assumed, neither do I believe it is harmless. Engaging in prostitution has its costs. Though prostitution is not necessarily a high-risk job, it is not a low-risk job either, most obviously because it carries with it a certain chance of catching sexually transmitted diseases. ${ }^{34}$ Further, prostitution is incompatible with sexually monogamous relationships, and it might well be a considerable psychological burden to have sexual contact with someone towards whom one is neither physically nor mentally attracted (this point is forcefully put by Marneffe ${ }^{32}$ ). These downsides, moreover, appear to be present regardless of our social or legal treatment of prostitution, and as such, they are genuine downsides to selling sex. ${ }^{\text {xiv }}$

\footnotetext{
${ }^{x i v}$ It is also possible that the above considered sources of harm, though they might individually be small, aggregate to become significant, either because they sum up or because they interact in unfortunate ways. The former I accept, though I maintain that the sum would be reasonably low. The latter would have to be positively argued for.
} 
Even on the weak significance view of sex, therefore, we need not agree with Lars $\mathrm{O}$ Ericsson, who claims that 'If two adults voluntarily consent to an economic arrangement concerning sexual activity and this activity takes place in private, it seems plainly wrong to maintain that there is something intrinsically wrong with it'. ${ }^{35}$ Though this might be a handy heuristic in a political context, and might serve as an argument against prohibition, consent is insufficient to ensure harmlessness. We can be harmed by things we consent to. That is why we are usually careful about giving our consent.

Even if we accept that there are genuine costs associated with prostitution, however, this does not give us sufficient reason to reject it. Before we reject it, we should also count its benefits. We should then compare the sum of total costs and benefits in prostitution with the sum of total costs and benefits in alternative occupations.

One benefit of prostitution is that it renders it possible for young people-who are the ones most likely to be poor-to earn a significant income without education and without investment costs, and to do so while keeping substantial parts of their spare time free to pursue other goals.

Another benefit is of a more general microeconomic nature: Imagine a woman, Caroline, who is very skilled at giving others sexual pleasure. Without prostitution, Caroline is free to give others sexual pleasure, but the only thing she herself can get out this is sexual pleasure in return. In economic terms, sexual pleasure is the only currency in which she can be paid. This currency restriction is suboptimal, for there might be many things Caroline needs more than she needs sexual pleasure. Perhaps she needs a new dishwasher or to pay for repairs to her car. If money is introduced as a medium of exchange, she can get this. If she can get money rather than sexual pleasure in return for sex, she can use the money she earns to buy herself a new dishwasher or repair the car. If these are more important to her than sexual pleasure is, then she has gained a higher value than she otherwise would.

A further advantage is that when money is introduced as a medium of exchange, Caroline can not only get more valuable things in return from sex: She can also get them from more people. Without prostitution, Caroline could only (as long as she wanted something in return) have sex with people who are fairly good at giving her sexual pleasure. With prostitution, she can enter profitable deals with a much larger pool of people. Now her sex partners need not be good at giving her sexual pleasure. They can be good at anything (teaching, writing, fixing computers, or selling newspapers), make money from doing what they are good at, and use the money to pay Caroline. Thus prostitution can give her something more valuable in return from a larger pool of people. This is a benefit that should be counted. ${ }^{\mathrm{xv}}$

How does prostitution fare in comparison to other occupations? When we compare prostitution with other occupations,

\footnotetext{
${ }^{\mathrm{xv}}$ In counting the benefits of prostitution, we should perhaps include the benefits on the side of the client. If we grant that clients are not harmed by buying sex, that sex (or physical intimacy) is a basic human need, and that for various reasons, many people will not have access to sex (or physical intimacy) other than if they pay, it seems that prostitution can satisfy a legitimate need. Due to the curious nature of human sexuality, moreover, it seems possible that a slight favor on the side of the prostitute could give a big surplus on the side of the client. Take a fetish such as feet licking. If a client is turned on by licking a prostitute's feet, and she charges $\$ 50$ for $20 \mathrm{~min}$ of licking, there could be a considerable surplus for both parties.
}

we see that in the same way that prostitution does not just have costs, other occupations do not just have benefits. This must be taken into account as long as the alternative to being a prostitute is not to get money for nothing, but to engage in other kinds of work.

When we compare the risks involved in prostitution with the risks involved in being a professional boxer, stunt artist, race car driver, deep sea diver, miner, policeman, or soldier-all of which are widely accepted occupations-it seems that prostitution is only moderately risky. The governmental New Zealand Accident Compensation Corporation interestingly categorises being a prostitute, which is legal in New Zealand, as safer than being an ambulance nurse. ${ }^{36}$ When we further compare the level of felt disgust in prostitution with the level of felt disgust in being a toilet cleaner, a sewer maintainer, a garbage worker, a coroner, or an embalmer-all of which are also widely accepted occupations-being a prostitute does at least not appear to be exceptionally disgusting. Sex, after all, is by and large a positive activity.

Thus it seems that when the whole context is taken into account, the harmful aspects of engaging in prostitution, though they are real and should not be neglected, are not as significant as we tend to assume. Indeed, it appears that for some-say, those who accept casual sex, have a high sex drive, need money and are able to work in a safe environment-selling sex could be a prudent option.

If this is correct, we must concede that it might be rational to engage in prostitution, and for some, irrational to opt out of it. This, if true, has significant implications for how, privately and professionally, we should view prostitution and treat those who engage in it.

\section{REPLIES TO TWO OBJECTIONS}

I have met two main objections to my argument. The first objection states that my argument runs contrary to basic, observable facts: prostitutes suffer tragic harms, such as depression, guilt, drug abuse and suicide attempts, and no amount of philosophical theorising can erase this.

This objection kicks in an open door, for I do not deny that prostitutes are harmed. Prostitutes are harmed. What I argue is that this harm has its main source, not in something intrinsic to prostitution, but in contingent external factors.

In 'The correlation with psychological problems argument' and 'The correlation with danger argument' I discussed the hypothesis that the extrinsic source of the harm suffered by prostitutes lies in how prostitutes are socially and legally treated. Proving this hypothesis would require sociological work beyond the scope of this paper. To try to isolate some of the harm brought about our treatment of prostitutes, however, consider the following thought experiment in which hairdressers are treated the same way prostitutes are treated: imagine that we were all brought up told that good girls are not hairdressers, that many of our common derogatory terms were synonyms for 'hairdresser', and that most people, upon seeing a hairdresser, would look away. Imagine that hairdressers had to live in fear of social exclusion if friends or family found out how they struggle to make ends meet, that no one would knowingly employ ex-hairdressers, and that landlords would terminate housing contracts if they discovered that their tenant is a hairdresser. Imagine that most hairdressers had to work on the street, in cars, or in the homes of strangers, and that if their work were organised, it were organised by criminals offering no work contracts, no sick leave and no insurance. 
In such a society, hairdressers would very likely suffer significant harms. There would be two reasons for this. Most obviously, the social and legal maltreatment would be a heavy burden to bear for those already engaged in hairdressing. Less obviously, but statistically just as important, the maltreatment would skew the sample of who become hairdressers in the first place. If hairdressers were maltreated, then only (or almost only) people who were already in serious trouble would find it worthwhile to become hairdressers. As such, if hairdressers were treated the same way prostitutes are treated, we should not be surprised to learn that hairdressing correlated with depression, suicide attempts, drug abuse and so on-even if, as we all know, hairdressing is not a harmful occupation.

If the way we treat prostitutes is so grim that it could seriously harm a perfectly innocent social group, we have reason to suspect that this indeed is what harms prostitutes. This reason grows in strength if, as I argue above, we have trouble finding anything intrinsic to prostitution that accounts for the harm. If this reasoning is sound, my thesis in this paper is compatible with the fact that, sadly, many prostitutes suffer serious harms.

The second objection states that my argument is utopian: that prostitution is a complex practice deeply entrenched in a long line of other social and psychological issues, such as gender inequality, poverty, power hierarchies and exploitation, and that in abstracting away from these, my argument relies on presuppositions so far from the actual world that the conclusions I draw have few, if any, practical implications. I am hard pressed, however, to see that my argument is utopian, at least in any problematic sense. First, my argument does not rely on traditionally utopian characteristics, such as endless resources, perfect knowledge, or unbreached rationality. Neither does it assume a society radically different from our own. For prostitution to become a profession of only moderate risks, what we need is a shift in our social and legal treatment of prostitutes. History proves, moreover, that our social and legal treatment of various social groups lies within our power to change. In less than two centuries we have, in large parts of the world, ended slavery, given men and women equal rights, and accepted homosexuality. It is important to remember, moreover, that these changes were made possible because some people dared to be a little utopian and abstracted away from their present context. We can all too easily hear the voice of someone opposed to homosexuality half a century ago proclaiming that homosexuality is deeply interrelated with various complex social and psychological factors (such as depression, exploitation, rape, disease, drug abuse and unstable families), that these form part of what homosexuality is, and that trying to assess homosexuality apart from them is hopelessly utopian. Today, we are glad someone dared question their assumptions and look beyond their immediate social context in their assessment of homosexuality. If my arguments in this paper are sound, we should approach prostitution in a similar manner, and be open for the possibility that prostitutes are harmed, not because prostitution is harmful, but because society at present seriously wrongs prostitutes.

Correction notice This article has been corrected since it was published Online First. In the last paragraph of 'The objectification argument' section, the sentence 'Thus P1 is doubtful on Mappes' account...' has been corrected. Also in the last paragraph of the paper, 'youth uncertainly' has been removed from the list of examples of 'psychological factors'.

Acknowledgements I would like to thank Tommy Knutsen, Martin Larsson, Thomas M. Johanson, Panos Dimas, Morten Magelssen, Mathias Sagdahl and Andreas Brekke Carlsson for useful comments. I also owe sincere thanks to the staff and users at the Oslo Prostitution Centre (ProSentret), where I worked on an outreach project while writing this paper.

\section{Competing interests None.}

Provenance and peer review Commissioned; externally peer reviewed.

\section{REFERENCES}

1 Weitzer R. The politics of prostitution in America. In: Weitzer R ed. Sex for sale. New York: Routledge, 2000:163-6.

2 Oxford English Dictionary, 2nd edn, s.v. "prostitution.". Oxford, UK.

3 Benatar D. Two views of sexual ethics: promiscuity, pedophilia, and rape. Public Aff Q 2002;16:191-201.

4 Bullough VL, McAnulty RD. The sex trade: exotic dancing and prositution. In: McAnulty RD, Burnette M eds. Sex and sexuality. Westport, Connecticut: Praeger, 2006:299-320.

5 Day S. On the game: women and sex work. London: Pluto Press, 2007:124-47.

6 Farley M, Barkan H. Prostitution, violence against women, and posttraumatic stress disorder. Women Health 1998;27:37-49.

7 Rian Ø. Seksualpsykologien som forsvant (The sexual psychology that disappeared). In: Brantsæter MC, Eikvam T, Kjær R, et al. eds. Norsk homoforskning. Oslo: Universitetsforlaget, 2001:104-40.

8 Moseng BU. Selvmordsatferd og seksuell orientering (Suicidal behavior and sexual orientation). In: Brantsæter MC, Eikvam T, Kjær R, et al. eds. Norsk homoforskning. Oslo: Universitetsforlaget, 2001:258-67.

9 Estes Y. Prostitution: a subjective position. In: Soble A, Power N eds. The philosophy of sex: contemporary readings. 5 edn. Lanham, Maryland: Rowman and Littlefield, 2008:353-65.

10 Sanders T, O'Neill M, Pitcher J. Prostitution: sex work, policy and politics. Los Angeles, California: Sage, 2009:33.

11 Bjørndahl U, Norli B. Fair game: a survey of the violence experienced by women working as prostitutes. Oslo: The Pro Centre, 2008:32-7.

12 Herek GM. Bad science in the service of stigma. In: Herek GM ed. Stigma and sexual orientation. London: Sage, 1998:223-55.

13 Almodovar NJ. For their own good: the results of the prostitution laws as enforced by cops, politicians and judges. Hastings Women's Law J 1999; 10:19-33.

14 Mappes T. Sexual morality and the concept of using another person. In: Soble A, Power $\mathrm{N}$ eds. The philosophy of sex: contemporary readings. 5 edn. Lanham. Maryland: Rowman and Littlefield, 2008:229-45.

15 Klepper H. Sexual exploitation and the value of persons. J Value Inq 1993;27:479-86.

16 Papadaki L. What is objectification? J Moral Phil, 2010;7:16-36.

17 Singer I. The nature of love, vol. 2: courtly and romantic. Chicago, Illinois: University of Chicago Press, 1984:382.

18 Nagel T. Sexual perversion. J Phil 1969:66:5-17.

19 Edlund L, Evelyn K. A theory of prostitution. J Polit Econ 2002;110:181-214.

20 Matthews R. Prostitution in London: an audit. Middlesex: Middlesex University Press, 1997:1-16

21 Levitt SD, Venkatesh SA. An empirical analysis of street-level prostitution. Unpublished manuscript cited with permission from the authors. 2007. http:// economics.uchicago.edu/pdf/Prostitution\%205.pdf (12 Jun 2011).

22 Levitt SD, Dubner SJ. Superfreakonomics. New York: HarperCollins Publishers, 2009:19-57.

23 U.S. Department of Labor. Changes in Basic Minimum Wages in Non-Farm Employment under State Law: Selected Years 1968 to 2011. http://www.dol.gov/ whd/state/stateMinWageHis.htm (9 May 2011).

24 Pateman C. Defending prostitution: charges against ericsson. Ethics 1983:93:561-5.

25 Barry K. Prostitution and sexuality. New York: New York University Press, 1995.

26 Farley M. 'Bad for the body, bad for the heart': prostitution harms women even if legalized or decriminalized. Violence Against Women 2004;10:1087-125.

27 Weitzer R. Flawed theory and method in studies of prostitution. Violence Against Women 2005;11:934-49.

28 Anderson SA. Prostitution and sexual autonomy: making sense of the prohibition of prostitution. Ethics 2002;112:748-80.

29 Satz D. Markets in women's sexual labor. Ethics 1995; 106:63-85.

30 de Marneffe P. Liberalism and prostitution. Oxford: Oxford University Press, 2010.

31 Liberto HR. Normalizing prostitution versus normalizing the alienability of sexual rights: a response to Scott A. Anderson. Ethics 2009;120:138-145.

32 Feinberg J. Voluntary euthanasia and the inalienable right to life. Philos Public Aff 1978;7:93-123.

33 Nussbaum M. 'Whether from reason or prejudice': taking money for sexual services. J Legal Stud 1998;27:693-723.

34 Aral SO, Mann JM. Commercial sex work and STD. Sex Transm Dis 1998;25:455-6.

35 Ericsson LO. Charges against prostitution: an attempt at a philosophical assessment. Ethics 1980:90:38-9.

36 New Zealand Accident Compensation Corporation, ACC Levy Rates Guidebook 2010/2011. Wellington: New Zealand, 2010:118. 